\title{
Composition and infraspecific variability of Artemisia herba-alba from southern Spain
}

\author{
Sofía Salido ${ }^{a}$, Luis R. Valenzuela ${ }^{\mathrm{b}}$, Joaquín Altarejos ${ }^{\mathrm{a}, *}$, \\ Manuel Nogueras ${ }^{\mathrm{a}}$, Aldolfo Sánchez ${ }^{\mathrm{a}}$, Eusebio Cano ${ }^{\mathrm{b}}$ \\ a Departamento de Química Inorgánica y Orgánica, Facultad de Ciencias Experimentales, Universidad de \\ Jaén, 23071 Jaén, Spain \\ b Departamento de Biología Animal, Biología Vegetal y Ecología, Facultad de Ciencias Experimentales, \\ Universidad de Jaén, 23071 Jaén, Spain
}

Received 9 September 2002 ; accepted 9 September 2003

\begin{abstract}
The composition of the essential oils of 16 individual plants of Artemisia herba-alba Asso ssp. valentina (Lam.) Marcl. (at the full bloom stage) growing wild in four different locations from southern Spain were investigated by capillary GC and GC-MS in combination with retention indices. Among the 60 identified constituents (accounting for $80.6-95.0 \%$ of the oils), 33 have been reported for the first time in Spanish A. herba-alba oil and 17 of them have not been previously described in $A$. herba-alba oil. From the analysis of the oil samples, it could be deduced that a noticeable chemical polymorphism typified this taxon. Four groups of essential oils exhibited a single compound with percentages near $30 \%$ or higher: davanone, 1,8-cineole, chrysanthenone and cis-chrysanthenol. Two further oil types showed $p$-cymene and cis-chrysanthenyl acetate as major components in moderate amounts (ca. $20 \%$ ). All of these types of essential oils have not been previously found in A. herba-alba from Spain and the appearance of such considerable amount of $p$-cymene is described here for the first time in A. herba-alba.
\end{abstract}

(C) 2003 Published by Elsevier Ltd.

Keywords: Artemisia herba-alba Asso ssp. valentina (Lam.) Marcl.; Asteraceae; Essential oil; Infraspecific variability; Davanone; 1,8-Cineole; Chrysanthenone; cis-Chrysanthenol; p-Cymene; cis-Chrysanthenyl acetate; $\alpha$-Pinene

\footnotetext{
${ }^{*}$ Corresponding author. Tel.: +34-953-002743; fax: +34-953-012141.

E-mail address: jaltare@ujaen.es (J. Altarejos).
} 


\section{Introduction}

The genus Artemisia L. (Asteraceae) comprises a variable number of species (from 200 to over 400, depending on the authors) found throughout the northern half of the world (Marco and Barberá, 1990). According to Tutin et al. (1976), the genus may be divided into sections Artemisia and Dracunculus, the former including the species Artemisia herba-alba Asso which is a medicinal and aromatic dwarf shrub that grows wild in arid areas of the Mediterranean basin, extending into northwestern Himalayas (Vernin et al., 1995). This plant is (relatively) abundant in the Iberian Peninsula and reaches highest population density in the centre of Spain spreading over the eastern, southeastern and southern Spain. This taxon grows wild on nitrofilous and gypsum-rich substrata. In southern Spain, A. herba-alba coexists with Artemisia barrelieri Besser, and the two species have often been confused. Two subspecies have been recognized in the Iberian Peninsula (Vallès-Xirau, 1987): A. herba-alba Asso subsp. valentina (Lam.) Marcl. and A. herba-alba Asso subsp. herba-alba which are known by the colloquial names of altamisa or boja. Both subspecies are widespread in the eastern Iberian Peninsula where it is common to find them growing together in the same place.

Since Cohen et al. (1972) used modern analytical techniques to analyze an $A$. herba-alba essential oil sample, the chemical composition of this oil has been studied and reviewed several times (Lawrence, 1989, 1993, 1995). Analysis of oil samples from Morocco had established the existence of at least seven chemotypes of the so-called armoise oil (Benjilali et al., 1982; Ouyahya et al., 1990; Lawrence, 1993). Other chemotypes were found in oil samples from Israel and the Sinai Desert (Segal et al., 1980; Feuerstein et al., 1986; Segal et al., 1987; Yashphe et al., 1987) and further types in oil samples from Egypt (El-Hawary et al., 1983; El-Sayed and Seida, 1990). Oil composition of this species from various areas of Algeria was used to characterize a chemotype different from those found in Morocco (Vernin and Merad, 1994; Vernin et al., 1995).

Concerning A. herba-alba growing in Spain, Gomis et al. (1979) investigated the composition (with no quantitative data) of the hydrocarbon fraction of a steamdistilled petrol extract prepared from plant material collected in the Valencia region. Villar et al. (1983), using packed-column GC analysis, studied an oil prepared from plants also collected in Valencia, with camphor and 1,8-cineole as the major constituents. Later Feuerstein et al. (1988) analyzed by GC-MS an oil obtained from plants collected in Madrid province and found that camphor, 1,8cineole, an unidentified sesquiterpene and $\alpha$-terpineol were the main constituents. More recently, our research group (Salido et al., 2001) investigated the oil composition of a sample of $A$. herba-alba ssp. valentina harvested in Jaén province during the full flowering period. Its composition was dominated by the sesquiterpene davanone and monoterpenes p-cymene, 1,8-cineole, chrysanthenone, cis-chrysanthenyl acetate, $\gamma$-terpinene, myrcene and camphor. In addition, an appreciable number of sesquiterpene lactones have been isolated in Spanish A. herba-alba (Gomis et al., 1979; Marco et al., 1989, 1990, 1992; Marco, 1989; Sanz et al., 1990a, 1990b). 
Aware of the noticeable chemical variability observed in A. herba-alba oils from northern Africa and Middle East, and the results found in our preliminary study on Spanish $A$. herba-alba oil, we inferred that it was likely that chemical diversity would be present in our territory. Thus, the aim of this work was to look into the chemical composition of Spanish essential oils in more depth in order to define the chemodiversity of the plant and the consequent potential value of this natural resource.

\section{Material and methods}

\subsection{Plant material}

Aerial parts of $A$. herba-alba ssp. valentina were collected at the flowering stage in December 1998 from four different representative populations located in Jaén province: "Ceal" (samples A; UTM: VG9376), "Quesada" (samples B; UTM: VG8684), "La Cerradura" (samples C; UTM: VG4274) and "Martos" (samples D; UTM: VG1369) (Table 1). Within each population, four individual plants were sampled at random (with a minimum distance of 15-20 m between each individual) and at the same time in order to reduce sampling siblings and seasonal variability. Each individual plant material consisted in 71.47-188.14 g of flowering tops. Voucher specimens of every plant sample were deposited at the Herbarium of the University of Jaén ( $A_{1}:$ JAEN62-373; $A_{2}$ : JAEN62-374; $A_{3}:$ JAEN62-375; $A_{4}$ : JAEN62-376; $B_{1}$ : JAEN62-377; B $_{2}$ : JAEN62-378; B ${ }_{3}$ : JAEN62-379; B $_{4}$ : JAEN62380; $\mathrm{C}_{1}$ : JAEN62-381; $\mathrm{C}_{2}$ : JAEN62-382; C 3 : JAEN62-383; C 4 : JAEN62-384; $\mathrm{D}_{1}$ : JAEN62-385; D $\mathrm{D}_{2}$ JAEN62-386; $\mathrm{D}_{3}$ : JAEN62-387; $\mathrm{D}_{4}$ : JAEN62-388). Samples of the plants were identified by two of us (L.R. Valenzuela, E. Cano) and Dr. Vallès-Xirau, Department de Productes Naturals, Facultat de Farmàcia, Universitat de Barcelona, Spain.

\subsection{Extraction of essential oils}

Plant samples were air-dried (12-18 days), chopped and steam distilled for $4 \mathrm{~h}$ using a double-bottom still assembled to a Clevenger-type collector. The oils obtained were recovered with diethyl ether, dried over anhydrous sodium sulfate, concentrated under a gentle stream of nitrogen and stored under nitrogen in sealed vials at $-20{ }^{\circ} \mathrm{C}$ until the moment of analysis. The oil yields, calculated from airdried vegetal material $\left(\mathrm{w} / \mathrm{w}\right.$ ), varied between $0.41 \%$ and $2.30 \%$ (see footnote ${ }^{\mathrm{c}}$ in Table 1).

\subsection{Gas chromatography analyses}

The GC analyses were carried out on a Varian 3350 gas chromatograph fitted with a methyl silicone HP-5MS (crosslinked 5\% PH ME Siloxane) capillary column $(30 \mathrm{~m} \times 0.25 \mathrm{~mm}$ i.d.; film thickness: $0.25 \mu \mathrm{m})$. The oven temperature was programmed from $50{ }^{\circ} \mathrm{C}$ to $250{ }^{\circ} \mathrm{C}$ at $3{ }^{\circ} \mathrm{C} / \mathrm{min}$. Carrier gas was He with a flow rate of $1.5 \mathrm{ml} / \mathrm{min}$. Temperatures of injector and FID detector were 250 and $300{ }^{\circ} \mathrm{C}$, 


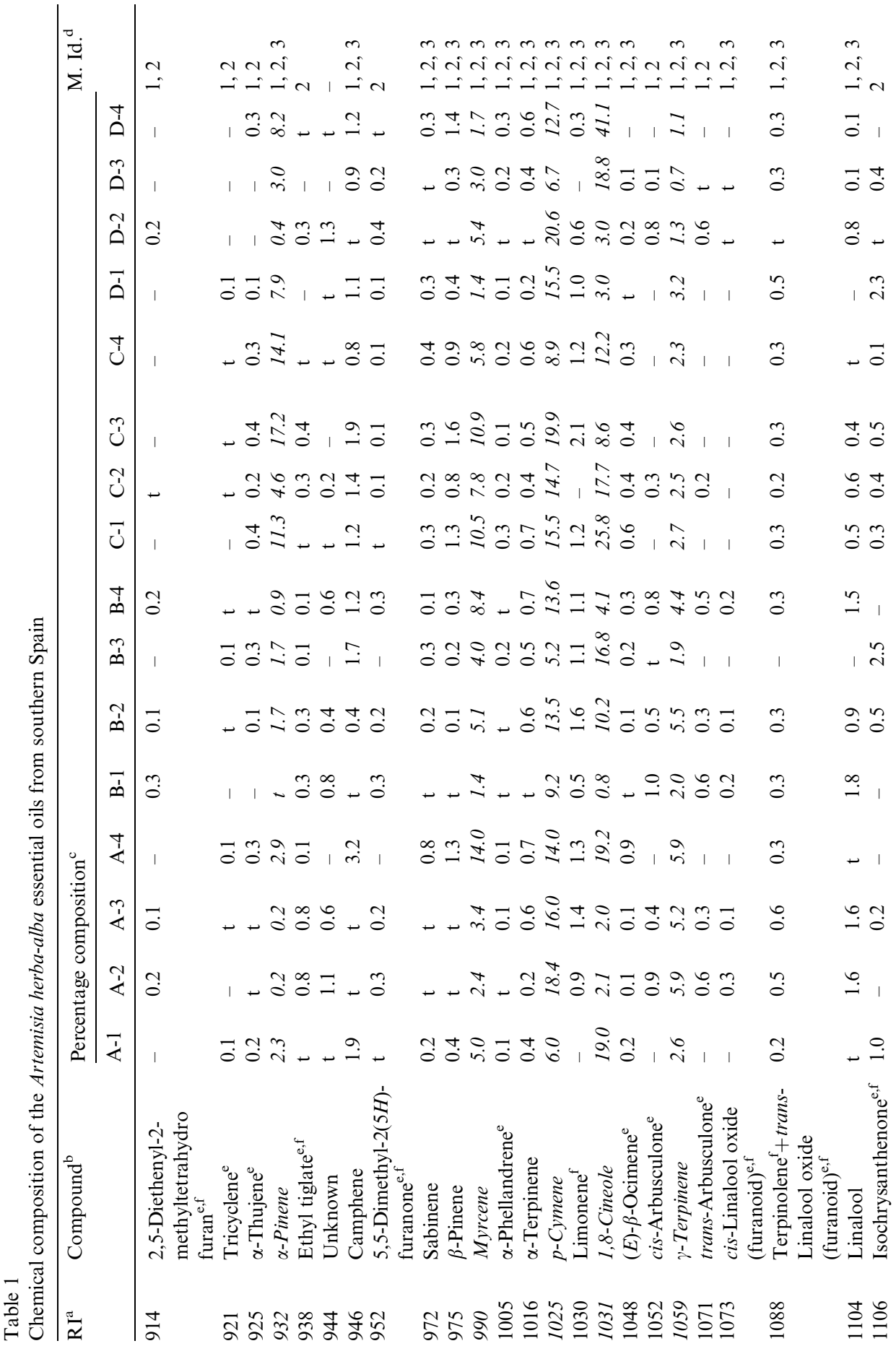




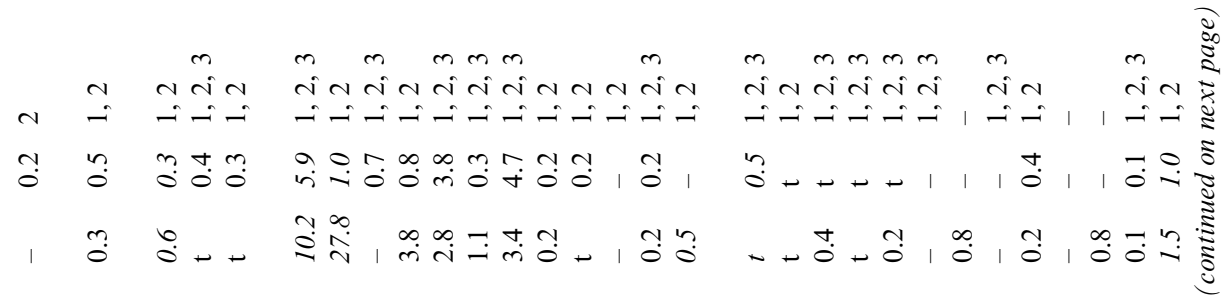

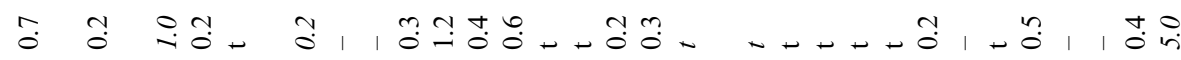

㓭+

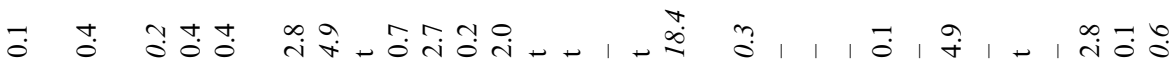

ڤె

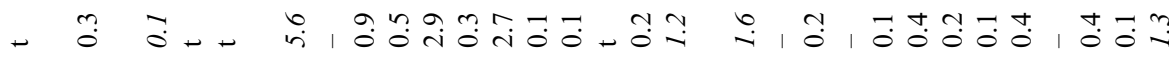

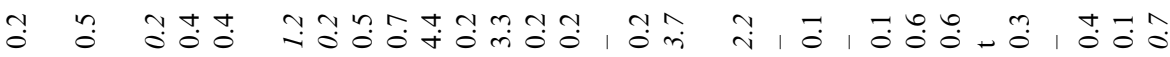

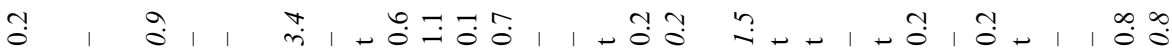

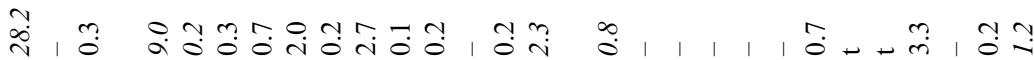

ڤุ

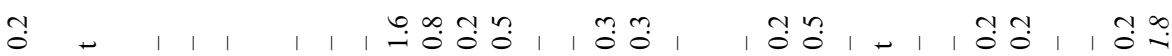

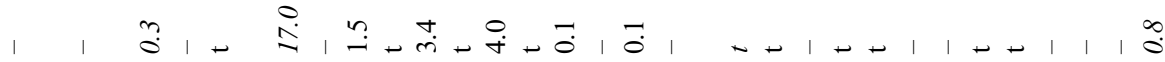

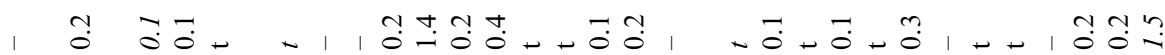

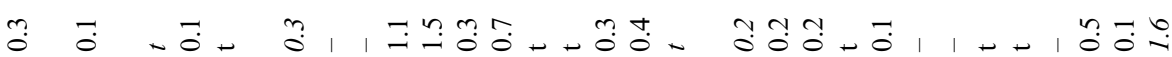

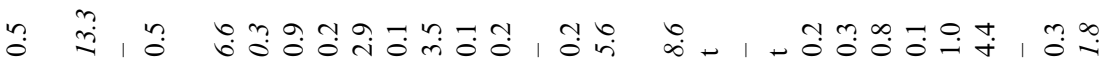

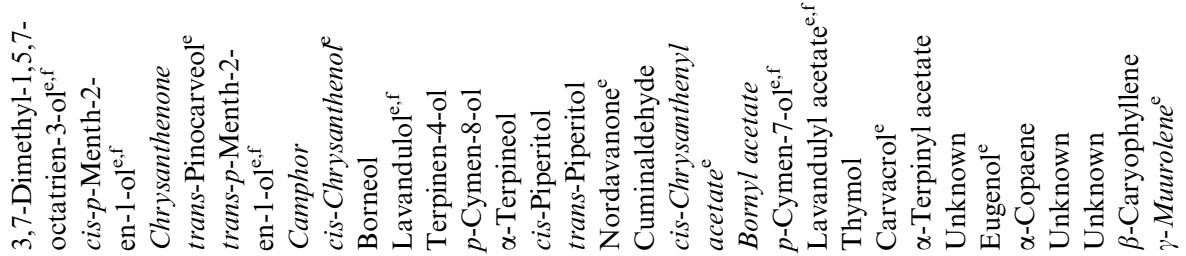

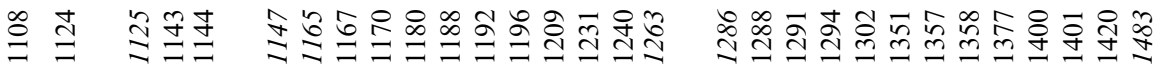




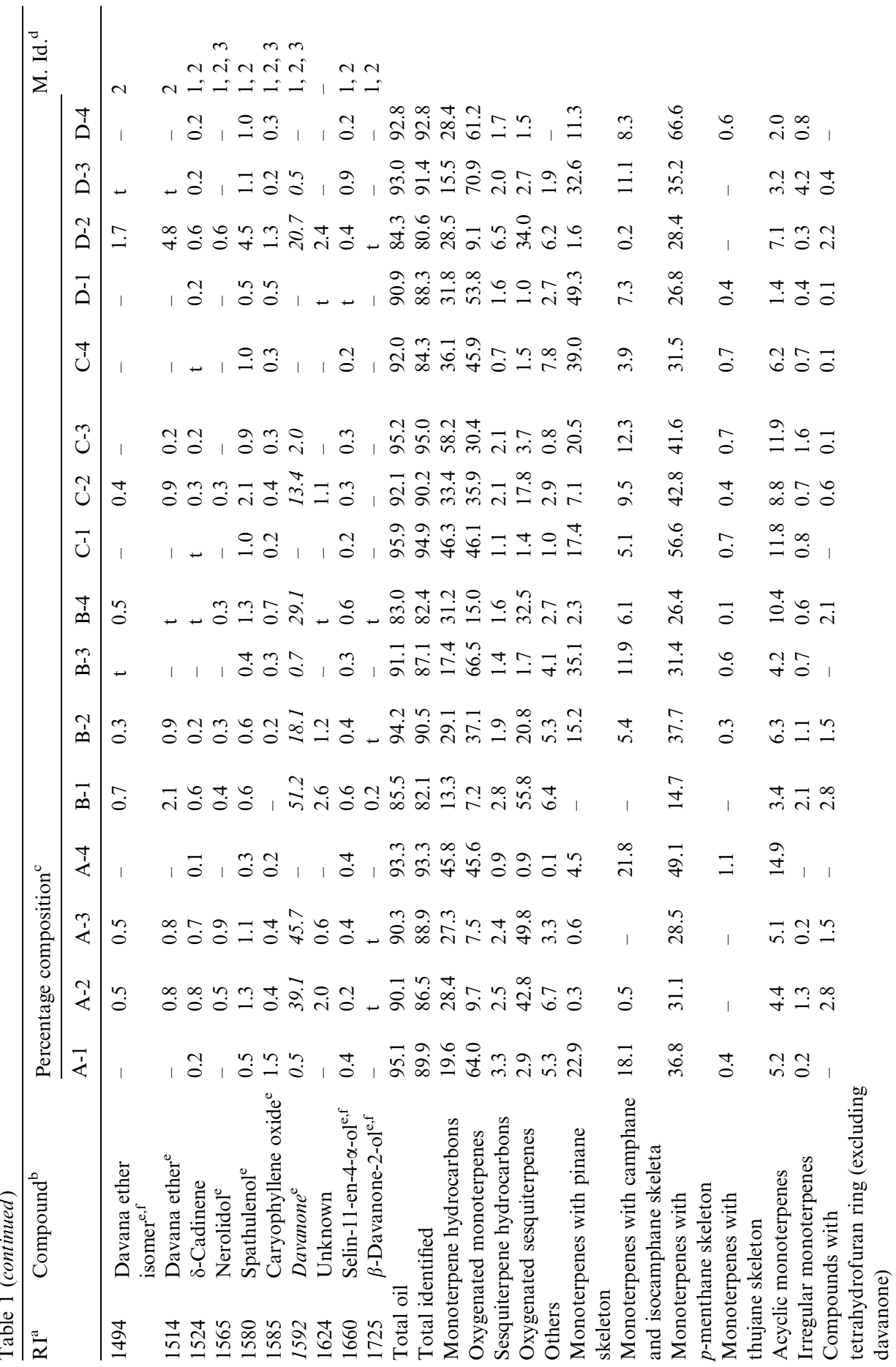




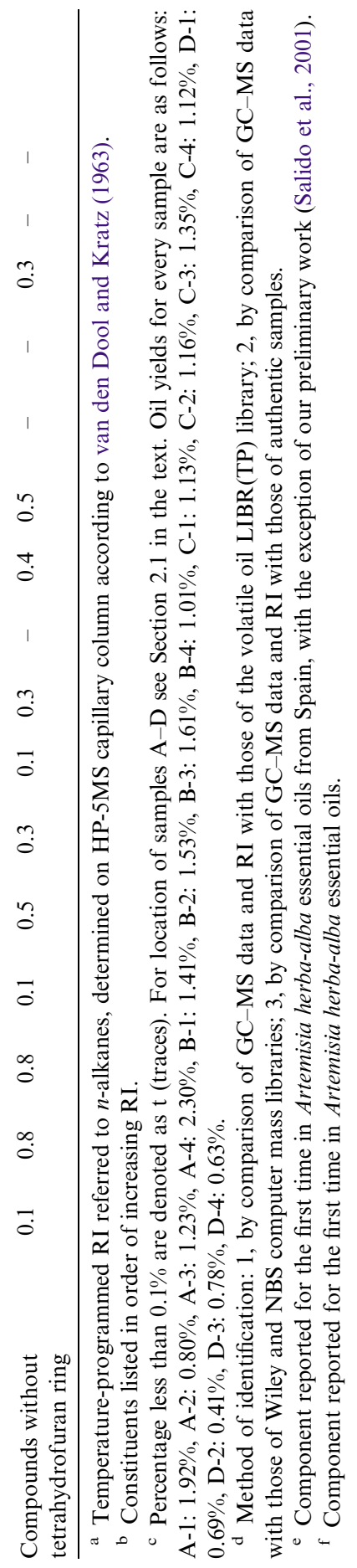


respectively. Oil samples were injected without solvent $(0.1 \mu \mathrm{l})$ using the split mode injection (1:60 ratio). Quantification of components was made on the basis of their GC peak areas without correction factors. Temperature-programmed retention indices (RI) were calculated using a homologous series of $n$-alkanes (van den Dool and Kratz, 1963).

\subsection{Gas chromatography-mass spectrometry analyses}

GC-MS analyses were performed on a Hewlett-Packard gas chromatograph (model 5890 II) coupled to a Hewlett-Packard mass spectrometer (model 5989 B). The GC unit was equipped with the same capillary column described in Section 2.3 and operating under the same conditions. Ion source temperature of the MS unit was $250{ }^{\circ} \mathrm{C}$ and mass spectra were recorded at an ionizing voltage of $70 \mathrm{eV}$ with a scan mass range of $m / z$ 35-300.

Identification of components was done by GC-MS using the volatile oil LIBR(TP) library coupled with RI (Adams, 1995) and both built-in Wiley and NBS computer mass libraries. GC-MS data of authentic standards together to their RI values (Section 2.3) and/or data reported in the literature were also used for further identification (Salido et al., 2001).

\section{Results and discussion}

In order to study the chemical composition and variability of the $A$. herba-alba ssp. valentina essential oils, 16 individual plants in bloom were collected from four different populations located in Jaén province (southern Spain). These four populations were selected from environmentally diverse areas where $A$. herba-alba grows abundantly. With the aim of identifying precisely the different chemotypes, our work was carried out on individual oils, obtained from plants collected at the same time, within the same ca. 100 m-long quadrant sampling area and, consequently, under exactly the same ecological conditions. The air-dried aerial parts of every plant material were steam distilled to afford 16 oil samples with oil yields ranged between $0.41 \%$ and $2.30 \%$ (Table 1 ).

Identification of the oil constituents was carried out by GC and GC-MS analyses in combination with RI. Table 1 shows the constituents of every oil sample listed in order of their elution from a low-polar capillary column. This study allowed the identification of 60 constituents (accounting for $80.6-95.0 \%$ of the oils), 33 of which being reported for the first time in Spanish $A$. herba-alba oil. To our knowledge, 17 of these components have not been previously described in A. herba-alba oil (see footnotes ${ }^{\mathrm{e} \text { and } \mathrm{f}}$ in Table 1). Among the most of 90 compounds identified in other $A$. herba-alba oils, and not detected in this study, the absence of $\alpha$-thujone and $\beta$-thujone is worth noting, as these ketones are common compounds in oils from Morocco, Israel or Algeria and even from Spain, where small amounts were detected in a sample from eastern Spain (Villar et al., 1983).

The GC analysis of the essential oils (Table 1) showed that there were significant quantitative and also qualitative differences. The oxygenated sesquiterpene 
davanone and the oxygenated monoterpene 1,8-cineole were found to be major components in 11 samples, the most abundant in 6 and the second most abundant in 5. Other oxygenated monoterpenes such as chrysanthenone, cis-chrysanthenol and cis-chrysanthenyl acetate were major components in 2, 1 and 1 occasions, respectively, and the monoterpene hydrocarbon $p$-cymene was also a major component once. In addition, $p$-cymene was the most often second major component (10 times) and myrcene and $\alpha$-pinene the third major components (4 and 3 times, respectively). In Table 1, those constituents with a percentage of $5 \%$ or higher in the oils appear in italics. Among these 12 constituents selected for comparisons 6 (1,8-cineole, $p$-cymene, $\alpha$-pinene, myrcene, $\gamma$-terpinene, $\gamma$-muurolene) were present in all samples. It is notable that cis-chrysanthenol, davanone and cis-chrysanthenyl acetate were absent from 7, 5 and 4 plants, respectively.

As the number of samples analyzed in this study is relatively small it is not possible to establish genuine chemotypes with accuracy. However, the scrutiny of all the information included in Table 1 allowed us to determine the presence of four groups exhibiting a single compound with a percentage near $30 \%$ or higher: davanone, 1,8-cineole, chrysanthenone and cis-chrysanthenol. In addition, two plant oils (C-3, C-4) have p-cymene (19.9\%) and cis-chrysanthenyl acetate $(18.4 \%)$ as major components, in appreciable amounts, and $\alpha$-pinene $(17.2 \%, 14.1 \%$, respectively) as the second component in both cases.

Four samples (A-2, A-3, B-1, B-4), among the 16 studied, had a davanone percentage ranged between $29.1 \%$ and $51.2 \%$. p-Cymene was the second major component $(9.2-18.4 \%)$ in all cases, and the third major components were $\gamma$-terpinene (A2, A-3), myrcene (B-4) and the unknown RI 1624 (B-1). Several compounds such as chrysanthenone, camphor, bornyl acetate, cis-chrysanthenol and chrysanthenyl acetate were absent in plant B-1 and the last two in other individuals of this group as well (Table 1). These davanone-type oils seem to be typified by (a) lower amounts of oxygenated monoterpenes $(7.2-15.0 \%)$ than the rest of the oils $(30.4-70.9 \%)$; (b) lower amounts of monoterpenes with the pinane skeleton $(0.0$ $2.3 \%$ ) than the rest of the oils $(4.5-49.3 \%)$; (c) the near absence of monoterpenes with camphane-isocamphane $(0.0-0.5 \%)$ and thujane $(0.0-0.1 \%)$ skeleta if compared with the rest of the oils $(3.9-21.8 \%$ and $0.0-0.7 \%$, respectively); (d) the presence of the relatively highest amounts of other compounds with a tetrahydrofuran ring (1.5-2.8\%) such as 2,5-diethenyl-2-methyltetrahydrofuran, 5,5-dimethyl-2 $(5 H)$ furanone, both arbusculones, both linalool oxides and nordavanone (Table 1). Furthermore, two plant oils (B-2, D-2) also had davanone as a major component but in lower amounts (18.1\% and $20.7 \%$, respectively). Davanone has been found to be the major constituent in some populations of $A$. herba-alba from Morocco (Benjilali et al., 1982; Lawrence, 1993) and a minor constituent in samples from the Sinai Desert and surroundings (Feuerstein et al., 1986; El-Sayed and Seida, 1990). This is the first time that davanone has been identified in an oil of Spanish origin, with the exception of our own preliminary work (Salido et al., 2001).

Two samples (C-1, D-4) had an appreciable percentage of 1,8-cineole $(25.8 \%$, $41.1 \%)$. The second and third major components were $p$-cymene $(15.5 \%, 12.7 \%)$ and $\alpha$-pinene $(11.3 \%, 8.2 \%)$. Several components such as davanone, $\beta$-davanone- 
2-ol, davana ether, nordavanone and the arbusculones are absent, and the percentages of camphor $(1.2 \%, 5.9 \%)$ and chrysanthenone $(0.2 \%, 0.3 \%)$ were rather low. These 1,8-cineole-rich oils seem to be characterized by (a) moderate amounts of monoterpenes with pinane $(17.4 \%, 11.3 \%)$ and camphane-isocamphane $(5.1 \%$, $8.3 \%$ ) skeleta, and (b) the absence of compounds with a tetrahydrofuran ring. In addition to samples $\mathrm{C}-1$ and D-4, 1,8-cineole reached considerable but lower amounts (17.7-19.2\%) in three more plant oils (A-1, A-4, C-2). 1,8-Cineole is one of the most common constituents in A. herba-alba essential oil and it has been reported in almost all samples described in the literature. It has been found as a major constituent in two populations from Israel (Feuerstein et al., 1986) and in one from Egypt (El-Sayed and Seida, 1990), and it was the second major component in oil samples from eastern and central Spain (Villar et al., 1983; Feuerstein et al., 1988).

Two samples (B-3, D-1) reached a notable content of chrysanthenone $(28.2 \%$, $36.4 \%$ ). The second major components were 1,8-cineole (B-3) and p-cymene (D-1), and the third major ones were camphor (B-3) and $\alpha$-pinene (D-1) (Table 1). Isochrysanthenone, cis-chrysanthenyl acetate and terpinen-4-ol were found in positions 8, 9 and 10, respectively, in both plants. These chrysanthenone-type oils (a) have lower amounts of monoterpenes with $p$-menthane skeleton $(26.8-31.4 \%)$ than the rest of the samples $(28.4-66.6 \%)$, and (b) lower amounts of acyclic monoterpenes (1.4-4.2\% vs. 2.0-14.9\%). Chrysanthenone has been described in essential oils from Spain (Feuerstein et al., 1988), Morocco (Benjilali et al., 1982; Ouyahya et al., 1990; Lawrence, 1993) and Algeria (Vernin et al., 1995; Lawrence, 1995), although it has been found as a major component $(51.4 \%)$ only once in Morocco (Lawrence, 1993) and at one stage $(54.5 \%)$ during the life cycle of Algerian $A$. herba-alba cultivars (Boutekedjiret et al., 1992).

Only sample D-3 reached a considerable percentage of cis-chrysanthenol $(27.8 \%)$. Other significant components were 1,8 -cineole $(18.8 \%)$, camphor $(10.2 \%)$ and $p$-cymene $(6.7 \%)$. This cis-chrysanthenol-rich oil achieved (a) higher amounts of oxygenated monoterpenes $(70.9 \%)$ and (b) irregular monoterpenes $(4.2 \%)$ than the rest of oils (7.2-66.5\% and $0.0-2.1 \%$, respectively) (Table 1). cis-Chrysanthenol is not a common component in $A$. herba-alba oils as it had not been found either in Spanish oils, before our preliminary contribution (Salido et al., 2001), or Moroccan or Egyptian oils. It has only been described in Algerian plants (Vernin et al., 1995) as a minor component and in a single plant from the Sinai Desert surroundings as a major component (Feuerstein et al., 1986).

p-Cymene $(19.9 \%)$, $\alpha$-pinene $(17.2 \%)$, myrcene $(10.9 \%), 1,8$-cineole $(8.6 \%)$ and camphor $(8.5 \%)$ are the main constituents of sample C-3 (Table 1). This oil is quite unusual for $A$. herba-alba because this is the first time that such considerable amounts of $p$-cymene and $\alpha$-pinene have been reported, although both compounds are common but minor components in oils from Spain (Gomis et al., 1979; Villar et al., 1983; Feuerstein et al., 1988), Morocco (Benjilali and Richard, 1980; Benjilali et al., 1982; Lemberg, 1982; Ouyahya et al., 1990; Lawrence, 1993), Israel (Feuerstein et al., 1986; Yashphe et al., 1987) and Algeria (Vernin et al., 1995). Furthermore, $p$-cymene is a significative component in all samples analyzed in this 
work (average percentage 13.2\%) and also $\alpha$-pinene which appears in a noticeable level, except in those samples belonging to the davanone-type oil.

cis-Chrysanthenyl acetate $(18.4 \%), \alpha$-pinene $(14.1 \%), 1.8$-cineole $(12.2 \%), p$ cymene $(8.9 \%)$ and myrcene $(5.8 \%)$ are the most relevant components in sample C4. This oil (a) has a high level of monoterpenes with the pinane skeleton (only greater in sample D-1) and (b) one of the lowest contents of sesquiterpenes if compared with the rest of samples (Table 1). cis-Chrysanthenyl acetate has been found to be the major constituent in some A. herba-alba oils from Morocco (Benjilali et al., 1982; Lawrence, 1993), Israel (Feuerstein et al., 1986; Yashphe et al., 1987) and Algeria (Boutekedjiret et al., 1992) and a minor constituent in other samples from Morocco (Ouyahya et al., 1990) and Algeria (Vernin et al., 1995). This monoterpenoid was reported for the first time in a Spanish oil in our previous work (Salido et al., 2001).

\section{Conclusion}

This work allowed us to confirm a very important infraspecific chemical variability in Spanish $A$. herba-alba. The significant amount of $p$-cymene found in one of the samples has being described here for the first time. The rest of the possible chemotypes (davanone, 1,8-cineole, chrysanthenone, cis-chrysanthenol, cischrysanthenyl acetate) are also new in Spanish $A$. herba-alba but already known in other Mediterranean areas; the davanone type has been found in Morocco, the 1,8cineole type in Israel and Egypt, the chrysanthenone type in Morocco and Algeria, the cis-chrysanthenol type in the Sinai area, and cis-chrysanthenyl acetate types in Morocco, Israel and Algeria. By contrast, the thujones-rich chemotypes (found in Morocco, Israel and Algeria) and the camphor type (found in Morocco, Egypt, Algeria and Spain) are not present in the plants studied here.

\section{Acknowledgements}

We wish to thank the Junta de Andalucia for financial support and Dr. Vallès-Xirau (Universitat de Barcelona, Spain) for verifying the identity of the voucher specimens.

\section{References}

Adams, R.P., 1995. Identification of Essential Oil Components by Gas Chromatography/Mass Spectroscopy. Allured Publishing Corporation, Carol Stream, IL.

Benjilali, B., Richard, H., 1980. Etude de quelques peuplements d'Armoise blanche du Maroc Artemisia herba-alba. Riv. Ital. EPPOS 62, 69-74.

Benjilali, B., Sarris, J., Richard, H., 1982. Nouveaux chémotypes d'Artemisia herba-alba. Sci. Aliment. 2, 515-527.

Boutekedjiret, C., Charchari, S., Belabbes, R., Bessiere, J.M., 1992. Contribution à l'étude de la composition chimique de l'huile essentielle d'Artemisia herba-alba Asso. Riv. Ital. EPPOS 3, 39-42. 
Cohen, A., Lavergne, J.P., Leblanc, A., Viallefont, P., 1972. Etude des constituants de Artemisia herbaalba "typica". Bull. Soc. Sci. Nat. Phys. Maroc 52, 1-19, (Chem. Abstr. 78:151543r).

El-Hawary, S.S., Hifrawy, M.S., Karawya, M.S., 1983. Essential oil of Artemisia herba-alba. In: IXth International Essential Oil Congress, Singapore.

El-Sayed, A.M., Seida, A.A., 1990. Comparative study of the major constituents of the essential oils of wild and cultivated Egyptian Artemisia herba-alba with those of plants produced abroad. Bull. Fac. Pharm. 28, 57-58.

Feuerstein, I., Müller, D., Hobert, K., Danin, A., Segal, R., 1986. The constitution of essential oils from Artemisia herba-alba populations of Israel and Sinai. Phytochemistry 25, 2343-2347.

Feuerstein, I., Danin, A., Segal, R., 1988. Constitution of the essential oil from an Artemisia herba-alba population of Spain. Phytochemistry 27, 433-434.

Gomis, J.D., Marco, J.A., Llinares, J.R.P., Parareda, J.S., Sendra, J.M., Seoane, E., 1979. Sesquiterpene lactones, waxes and volatile compounds from Artemisia herba-alba subspecies valentina. Phytochemistry $18,1523-1525$.

Lawrence, B.M., 1989. Armoise oil. In: Natural Flavor and Fragrance Materials. Perfumer and Flavorist (Ed.), Essential Oils 1981-1987. Allured Publishing Corporation, Wheaton, IL, p. 1, pp. 53-55.

Lawrence, B.M., 1993. Armoise oil. Natural Flavor and Fragrance Materials. In: Perfumer and Flavorist (Ed.), Essential Oils 1988-1991. Allured Publishing Corporation, Carol Stream, IL, pp. 52-54.

Lawrence, B.M., 1995. Armoise oil. Natural Flavor and Fragrance Materials. In: Perfumer and Flavorist (Ed.), Essential Oils 1992-1994. Allured Publishing Corporation, Carol Stream, IL, pp. 179-180.

Lemberg, S., 1982. Armoise-Artemisia herba-alba. Perfum. Flavor. 7, 58-63.

Marco, J.A., 1989. Sesquiterpene lactones from Artemisia herba-alba subsp. herba-alba. Phytochemistry 28, 3121-3126.

Marco, J.A., Barberá, O., 1990. Natural products from the genus Artemisia L. In: Atta-ur-Rahman (Ed.), Studies in Natural Products Chemistry, vol. 7. Elsevier Science Publishers BV, Amsterdam, pp. 201-264.

Marco, J.A., Sanz, J.F., Cardá, M., 1989. Revision of the structure of torrentin. Phytochemistry 28, 2505-2506.

Marco, J.A., Sanz, J.F., Falcó, E., Jakupovic, J., Lex, J., 1990. New oxygenated eudesmanolides from Artemisia herba-alba. Tetrahedron 46, 7941-7950.

Marco, J.A., Sanz, J.F., Cardá, M., Lex, J., 1992. The stereochemistry and solid state conformation of the eudesmanolides torrentin and 11-epi-torrentin. J. Nat. Prod. 55, 476-481.

Ouyahya, A., Negre, R., Viano, J., Lozano, Y.F., Gaydou, E.M., 1990. Essential oils from Moroccan Artemisia negrei, A. mesatlantica and A. herba-alba. Lebensm.-Wiss. u.-Technol. 23, 528-530.

Salido, S., Altarejos, J., Nogueras, M., Sánchez, A., 2001. Chemical composition of the essential oil of Artemisia herba-alba Asso ssp. valentina (Lam.). Marcl. J. Essent. Oil Res. 13, 221-224.

Sanz, J.F., Castellano, G., Marco, J.A., 1990a. Sesquiterpene lactones from Artemisia herba-alba. Phytochemistry $29,541-545$.

Sanz, J.F., Falcó, E., Marco, J.A., 1990b. Further news sesquiterpene lactones from Artemisia herbaalba subsp. valentina. J. Nat. Prod. 53, 940-945.

Segal, R., Breuer, A., Feuerstein, I., 1980. Irregular monoterpene alcohols from Artemisia herba-alba. Phytochemistry 19, 2761-2762.

Segal, R., Feuerstein, I., Danin, A., 1987. Chemotypes of Artemisia herba-alba in Israel based on their sesquiterpene lactone and essential oil constitution. Biochem. Syst. Ecol. 15, 411-416.

Tutin, T.G., Persson, K., Gutermann, W., 1976. Artemisia L. In: Tutin, T.G., Heywood, V.H., Burges, N.A., Moore, D.M., Valentine, D.H., Walters, S.M., Webb, D.A. (Eds.), Flora Europaea, vol. 4. Cambridge University Press, Cambridge, pp. 178-186.

Vallès-Xirau, J., 1987. Contribución al estudio de las razas Ibéricas de Artemisia herba-alba Asso. Bol. Soc. Brot., Sér. 60, 5-27.

Dool, van den Dool, H., Kratz, P.D., 1963. A generalization of the retention index system including linear temperature programmed gas-liquid partition chromatography. J. Chromatogr. 11, 463-471.

Vernin, G., Merad, L.O., 1994. Mass spectra and Kovats indices of some new cis-chrysanthenyl esters found in the essential oil of Artemisia herba-alba from Algeria. J. Essent. Oil Res. 6, 437-448. 
Vernin, G., Merad, O., Vernin, G.M.F., Zamkotsian, R.M., Párkányi, C., 1995. GC-MS analysis of Artemisia herba-alba Asso essential oils from Algeria. In: Charalambous, G. (Ed.), Food Flavors: Generation, Analysis and Process Influence. Elsevier Science BV, Amsterdam, pp. 147-205.

Villar, A., Calduch, M.L., Zafra-Polo, M.C., 1983. Aceites esenciales de diversas especies de Artemisia. Ars Pharm. 24, 149-159.

Yashphe, J., Feuerstein, I., Barel, S., Segal, R., 1987. The antibacterial and antispasmodic activity of Artemisia herba-alba Asso. II. Examination of essential oils from various chemotypes. Int. J. Crude Drug Res. 25, 89-96. 